\title{
Evaluasi Implementasi Program Kelas Ibu Hamil (KIH)
}

\section{The Evaluation Implementation of Pregnant Women Class Program}

\author{
Sudarmi \\ Jurusan Kebidanan, Politeknik Kesehatan Tanjung Karang, Indonesia
}

\section{ARTICLE INFO}

\section{Article history}

Received date 14 Sep 2021

Revised date 23 Nov 2021

Accepted date 26 Nov 2021

\section{Keywords:}

Evaluation; Implementation; Pregnant Women Class $(\mathrm{KIH})$.

\section{Kata kunci:}

Evaluasi; Implementasi; Kelas Ibu Hamil (KIH).

\author{
ABSTRACT/ ABSTRAK
}

\begin{abstract}
Pregnant Women Class $(\mathrm{KIH})$ is meant to learn together about health for pregnant women, in the form of face-to-face in groups that aim to improve their knowledge and skills. To see it's the effectiveness of implementation as an effort to develop KIH, it is necessary to evaluate the implementation of KIH. Type of research Evaluation with an evaluation model used to find CIPP which aims to find the Context, Inputs, Processes, and Products of KIH. The technique of collecting data was using study documentation, in-depth interview, observation, and active participation, using a research protocol. Data analysis by data validity and classifying data according to focus and research questions, combining data in the form of matrices or tables and triangulation strategies to describe the results of the analysis and research findings. The results of the evaluation, objectives, process, and implementation of the $\mathrm{KIH}$ as a whole have been carried out, but not all activities are by the implementation guidelines that have been set. The focus of activities is not appropriate and requires improvement by evaluation standards, namely the formulation of objectives, setting targets, infrastructure, and the $\mathrm{KIH}$ implementation team of facilitators. Recommendations for the implementing team should come from Interprofessional Collaboration (IPC), in the process of implementing the $\mathrm{KIH}$ it is expected and suitable with the Standard Operating Procedure (SOP), the need to develop $\mathrm{KIH}$ model that is needed for high-risk pregnant women.
\end{abstract}

Kelas Ibu Hamil (KIH) merupakan sarana untuk belajar bersama tentang kesehatan bagi ibu hamil, dalam bentuk tatap muka dalam kelompok yang bertujuan untuk meningkatkan pengetahuan dan keterampilan ibu hamil. Untuk melihat keefektifan pelaksanaan dalam upaya mengembangan KIH maka perlu dilakukan evaluasi pelaksanaan KIH. Jenis penelitian evalusi dengan model evaluasi yang digunakan ialah CIPP yang bertujuan untuk mengevaluasi konteks, input, proses dan produk KIH. Teknik mengumpulkan data menggunakan studi dokumentasi, Indept wawancara, observasi,dan partisipasi aktif, dengan menggunakan protocol research. Analisis data dengan validasi data, mengklasifikasikan data sesuai fokus dan pertanyaan penelitian, penggabungan data dalam bentuk matrik atau tabel serta strategi triangulasi untuk dideskripsikan hasil analisis dan temuan penelitiannya. Hasil evaluasi, Tujuan, proses dan pelaksanaan KIH secara keseluruhan telah dilaksanakan, tetapi belum seluruh kegiatan sesuai dengan standar pedoman pelaksanaan yang telah ditetapkan. Fokus kegiatan yang belum sesuai dan memerlukan perbaikan sesuai dengan standar kriteria evaluasi yaitu perumusan tujuan, penetapan target, sarana prasarana dan tim fasilitator pelaksana KIH. Rekomendasi tim pelaksana sebaiknya Interprofesional kalaborasi (IPC), dalam proses pelaksanaan KIH diharapkan sesuai dengan Standar Operasional Prosedur (SOP), perlunya pengembangan model KIH yang diperuntukkan bagi ibu hamil yang beresiko tinggi.

ting i.

Corresponding Author:

Sudarmi

Jurusan Kebidanan, Politeknik Kesehatan Tanjung Karang, Indonesia

Email: sudarmi@poltekkes-tjk.ac.id

\section{PENDAHULUAN}

Prioritas program pembangunan kesehatan di Indonesia saat ini adalah upaya peningkatan derajat kesehatan Ibu dan anak, terutama pada kelompok yang paling rentan terhadap kesehatan yaitu ibu hamil, bersalin dan bayi pada masa perinatal. Salah satu upaya pemerintah dalam memberikan edukasi kesehatan pada ibu hamil dengan membuka kelas ibu hamil. KIH 
merupakan sarana untuk belajar bersama tentang kesehatan bagi ibu hamil, dalam bentuk tatap muka dalam kelompok bertujuan meningkatkan pengetahuan dan keterampilan ibu hamil (Kementerian Kesehatan RI, 2014).

Pemberian Edukasi kesehatan di kelas ibu hamil merupakan langkah kegiatan preventif di tingkat pelayanan kesehatan dasar primer dengan tujuan meningkatkan pengetahuan pencegahan terjadinya komplikasi kehamilan dan persalinan yang merupakan penyebab utama kematian ibu di Indonesia (Suarayasa, 2020). Proses edukasi merupakan upaya mengubah perilaku melalui pemberian informasi untuk mencapai derajat kesehatan (Fenstein, et al, 2006). Tujuan edukasi kesehatan untuk memberikan informasi kesehatan kepada seseorang agar memotivasi bergaya hidup sehat ke arah yang lebih positif. (Gueguen, J, 2010).

Edukasi kesehatan merupakan berbagai kombinasi pengalaman belajar yang dirancang untuk membantu individu dan komunitas memperbaiki kesehatan mereka, dengan meningkatkan pengetahuan atau sikap yang memengaruhi mereka (WHO, 2015). Dengan meningkatnya pengetahuan dan sikap ibu diharapkan ibu hamil dapat mencegah komplikasi kehamilan yang merupakan penyebab utama kematian ibu hamil (Suarayasa. K, 2020). Sehingga diharapkan berdampak terjadinya penurunan AKI di Indonesia, yaitu di tahun 2024 di targetkan penurunan menjadi 183/100.000 kelahiran hidup dan di tahun 2030 di harapkan dapat turun menjadi 131/100.000 kelahiran hidup (WHO, UNICEF, UNFPA, World Bank Group and The United Nations Population Division, 2019).

Pemerintah Kabupaten lampung selatan telah melaksanakan program $\mathrm{KIH}$, jumlah kelas ibu hamil yang ada saat ini sebanyak $297 \mathrm{KIH}$ dan dari 27 Puskesmas 100\% telah melaksanakan kelas ibu hamil. Tenaga kesehatan yang terlibat langsung dalam pelaksanaan Kelas Ibu hamil berjumlah 1513 tenaga kesehatan, dengan jumlah tenaga kesehatan terbanyak tenaga bidan 652 bidan $(43,09 \%)$. Selain itu dalam pelaksanaan kelas ibu hamil di bantu oleh sejumlah 5173 Kader Kesehatan yang tersebar di seluruh Desa dan di kelurahan (Dinas Kesehatan Kabupaten Lampung Selatan, 2019). Pedoman fasilitator dalam pemberian materi edukasi menggunakan buku KIA, buku ini berisikan informasi dan catatan penting pada ibu hamil dan keluarga nya tentang kesehatan ibu dan anak selama kehamilan (Kementerian Kesehatan RI, 2020).

Prosedur langkah-pelaksanaan kelas ibu hamil yang dilakukan saat ini mulai dari perencanaan sampai evaluasi menurut pengamatan penulis perlu di lakukan evaluasi dan kajian, untuk dijadikan bahan dasar pengembangan model kelas ibu hamil. Hal ini sejalan dari Hasil Telaah literatur/penelitian oleh Fuada \& Setyawati (2016) yang merekomendasi perlunya mengubah strategi KIH yang dilaksanakan saat ini, karena strategi yang ada dikhawatirkan sulit untuk menangkap peluang dan memperbaiki kinerja KIH.

\section{METODE}

Jenis penelitian evaluasi model evaluasi yang digunakan ialah Context (konteks), Input (input), Process (proses), dan Product (produk) (CIPP) yang bertujuan untuk mengevaluasi implementasi program kelas ibu hamil (KIH). Metode yang digunakan dalam penelitian ini adalah kualitatif. Waktu penelitian dilaksanakan Bulan Mei s/d Oktober 2020. Lokasi di Kabupaten Lampung Selatan di lima Lokasi Puskesmas hasil random lokasi dari 17 Puskesmas yang ada. Sumber data dari informan/responden yang terkait dalam kegiatan KIH (Kasie Kesehatan keluarga \& Gizi, Kepala Puskesmas, penanggung jawab program KIH dan dokter atau bidan pelaksana KIH). Teknik mengumpulkan data studi dokumentasi, indept wawancara, dan observasi partisipan, ketiga teknik tersebut, menggunakan protocol research.

Teknik analisis data dari Yin (2012) dengan pengujian kevalidan data, mengklasifikasikan data sesuai sub fokus dan pertanyaan penelitian, penggabungan data dalam bentuk tabel dan membuat kesimpulan yang berbasis data. Selain itu juga menggunakan strategi triangulasi (sumber, metode teori). Penelitian ini telah mendapatkan persetujuan kaji etik penelitian kesehatan dari Politeknik Kesehatan Tanjung Karang dengan Nomor: 256/KEPK-TJK/IV/2020. 
Tabel 1. Fokus dan Sub Fokus dan Aspek Evaluasi Penelitian

\begin{tabular}{|c|c|c|}
\hline No & Komponen (Fokus) Evaluasi & Aspek yang dievaluasi \\
\hline \multicolumn{3}{|c|}{ Konteks } \\
\hline 1 & Tujuan & Tujuan Penyelenggaraan Kelas Ibu Hamil \\
\hline 2 & Dukungan stakeholders & Dukungan stakeholders terkait penyelenggaraan $\mathrm{KIH}$ \\
\hline 3 & Potensi & Identifikasi potensi mendukung $\mathrm{KIH}$ \\
\hline \multicolumn{3}{|c|}{ Input } \\
\hline 4 & $\begin{array}{l}\text { Dasar pelaksanaan pedoman } \\
\text { dan pemetaan } \mathrm{KIH}\end{array}$ & $\begin{array}{l}\text { Dasar pelaksanaan kegiatan (peraturan dan dasar hukum), } \\
\text { Pedoman penentuan target dan sasaran KIH \&Pemetaan KIH }\end{array}$ \\
\hline 5 & Pengalokasian Sumber Daya & $\begin{array}{l}\text { Pengalokasian Sumber Daya (Tempat pelaksanaan, sarana kegiatan, } \\
\text { Pendanaan dan Perencanaan KIH tingkat Puskesmas dan Desa }\end{array}$ \\
\hline 6 & Perencanaan & $\begin{array}{l}\text { Penanggung jawab program, penentuan tim, penetapan target yang mengikuti } \\
\text { KIH, Pembagian jadwal dan Materi serta penetapan fasilitator }\end{array}$ \\
\hline \multicolumn{3}{|r|}{ 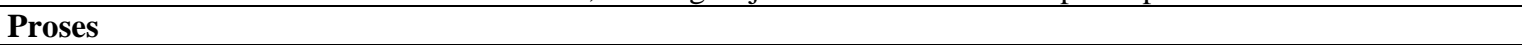 } \\
\hline 7 & Sosialisasi & Sosialisasi KIH di tingkat Desa \\
\hline 8 & Pelaksanaan pertemuan $\mathrm{KIH}$ & Pelaksanaan Pemberian edukasi di KIH \&Pelaksanaan Senam hamil \\
\hline 9 & Pencatatan dan Pelaporan & Sistem pencatatan dan pelaporan dalam pelaksanaan program \\
\hline 10 & Monitoring dan Evaluasi & Sistem monitoring dan evaluasi yang dilaksanakan \\
\hline 11 & Rencana indak Lanjut & Perencanaan tindak lanjut setelah selesai paket kelas ibu \\
\hline \multicolumn{3}{|c|}{ Produk } \\
\hline 12 & Capaian Target KIH & Jumlah Ibu hamil yang teredukasi program KIH \\
\hline 13 & Capaian K1-K4. & Jumlah ibu hamil yang melakukan kunjungan pertama dan K4 \\
\hline 14 & $\begin{array}{l}\text { Rencana persalinan di faskes } \\
\text { dan Petkes }\end{array}$ & $\begin{array}{l}\text { Jumlah ibu hamil yang merencanakan bersalin di fasilitas \& petugas } \\
\text { kesehatan }\end{array}$ \\
\hline 15 & Pencapaian $\mathrm{P} 4 \mathrm{~K}$ & Jumlah ibu hamil yang merencanakan $\mathrm{P} 4 \mathrm{~K}$ \\
\hline
\end{tabular}

\section{HASIL}

\section{Komponen Konteks}

\section{Tujuan Program Kelas Ibu Hamil (KIH)}

Tujuan program KIH ditetapkan oleh Dinas Kesehatan Lampung Selatan berdasarkan buku petunjuk pelaksanaan KIH tahun 2014. Tujuan telah didefinisikan dengan baik, dinyatakan dengan kalimat operasional, tujuan dirumuskan secara bersama serta dipahami oleh semua tim pelaksana.
Tetapi rumusan tujuan belum memiliki standar yang jelas dalam Batasan target dan waktu.

\section{Dukungan Stakeholders}

Perumusan tujuan program $\mathrm{KIH}$ sudah melibatkan stakeholders dan leading sektor baik internal maupun eksternal. Sektor internal yang terlibat: SKPD terkait dengan program KIH, Puskesmas, PMB dan bidan Desa. Sektor eksternal diantaranya: BPKB,PMD, Kecamatan, Desa, PKK, serta tokoh masyarakat.

Tabel 2. Distribusi Potensi Pendukung KIH

\begin{tabular}{|c|c|c|c|c|c|c|c|}
\hline No & Profesi & $\begin{array}{c}\text { PKM } \\
\text { T. Bintang }\end{array}$ & $\begin{array}{c}\text { PKM } \\
\text { Penengahan }\end{array}$ & $\begin{array}{c}\text { PKM } 3 \\
\text { Ketapang }\end{array}$ & $\begin{array}{c}\text { PKM } \\
\text { Way urang }\end{array}$ & $\begin{array}{c}\text { PKM } \\
\text { Krng anyar }\end{array}$ & Jumlah \\
\hline \multicolumn{8}{|c|}{ Tenaga Kesehatan } \\
\hline 1 & Dokter & 8 & 2 & 3 & 2 & 2 & 17 \\
\hline 2 & Dokter Gigi & 1 & 1 & 0 & 1 & 1 & 4 \\
\hline 2 & Bidan & 19 & 42 & 37 & 40 & 35 & 173 \\
\hline 3 & Perawat/PromKes & 6 & 21 & 20 & 15 & 15 & 77 \\
\hline 4 & Promkes & 1 & 1 & 1 & 2 & 1 & 6 \\
\hline 5 & Ahli Gizi & 2 & 1 & 3 & 1 & 2 & 9 \\
\hline 6 & Ahli Tenaga Lab & 2 & 2 & 2 & 1 & 2 & 9 \\
\hline 7 & Ahli kes-ling & 2 & 1 & 1 & 2 & 2 & 8 \\
\hline 8 & Apoteker & 1 & 2 & 1 & 1 & 2 & 7 \\
\hline \multirow[t]{2}{*}{9} & Lain-lain & 14 & 16 & 8 & 15 & 17 & 70 \\
\hline & Jumlah & 56 & 89 & 77 & 78 & 80 & 380 \\
\hline \multicolumn{8}{|c|}{ Desa } \\
\hline & Desa & 9 & 22 & 17 & 14 & 12 & 74 \\
\hline \multicolumn{8}{|c|}{ Kelas Ibu Hamil } \\
\hline & Kelas ibu Hamil & 9 & 22 & 17 & 15 & 12 & 75 \\
\hline \multicolumn{8}{|c|}{ Bidan Desa } \\
\hline & Bidan Desa & 10 & 22 & 17 & 14 & 20 & 83 \\
\hline \multicolumn{8}{|c|}{ Kader Kesehatan } \\
\hline & Kader Kesehatan & 185 & 289 & 225 & 370 & 295 & 1364 \\
\hline
\end{tabular}


Dari tabel 2 tenaga kesehatan yang paling terbanyak tersedia di tingkat Puskesmas adalah tenaga Bidan sejumlah 173 Bidan (45\%) distribusi tenaga kesehatan yang ada di setiap puskesmas sudah tersedia beberapa profesi tenaga kesehatan untuk pelaksana program KIH. Jumlah Desa 74 Desa sebanding dengan jumlah kelas ibu hamil 75. Seluruh Desa terdapat bidan Desa dengan Jumlah bidan desa 83 bidan. Jumlah kader kesehatan yang membantu pelaksanaan KIH sebanyak 1364 kader yang tersebar di setiap desa.

\section{Komponen Input}

\section{Dasar Pelaksanaan Pedoman dan Pemetaan KIH}

Dasar pelaksanaan kegiatan program KIH sesuai dengan standar yang ditetapkan oleh pusat, dengan berpedoman pada buku panduan pelaksanaan Kelas Ibu Hamil yang di keluarkan Kemenkes RI tahun 2014. Acuan perumusan tujuan didasarkan atas: Renstra Kemenkes RI tahun 2020 dan capaian misi kedua Dinas Kesehatan Lampung Selatan (2020) yaitu: meningkatkan kualitas Sumber Daya Manusia (SDM) melalui pelayanan pendidikan dan kesehatan yang baik, terjangkau dan proaktif dan Kebijakan-kebijakan dari kepala daerah kabupaten Lampung Selatan. Pedoman penetapan target sasaran ibu hamil yang mengikuti kelas ibu hamil $(\mathrm{KIH})$.

Pedoman penetapan mengacu pada pedoman penetapan target dan sasaran dari pusat. Sasaran KIH adalah ibu hamil yang usia kehamilan 20-32 minggu, target diharapkan seluruh puskesmas membuka KIH. Jumlah target partisipasi ibu hamil mengikuti KIH belum ditargetkan, penentuan target di setiap Puskesmas berbeda-beda disesuaikan dengan jumlah sasaran dan kemampuan tiap Puskesmas untuk menjangkau sasaran. Gambaran jumlah ibu hamil saat ini dan target yang ditetapkan untuk mengikuti KIH di setiap Puskesmas dapat dilihat pada tabel 3 .

Tabel 3. Jumlah Ibu Hamil per Juli 2020 dan Target KIH

\begin{tabular}{lrrr}
\hline \multirow{2}{*}{ PUSKESMAS } & \multicolumn{2}{c}{$\begin{array}{c}\text { Jumlah } \\
\text { Ibu Hamil }\end{array}$} & \multicolumn{2}{c}{ Target } \\
\cline { 3 - 4 } & \multicolumn{1}{c}{ Target } & Jumlah \\
\hline Tj.Bintang & 868 & 50 & 434 \\
Penengahan & 551 & 80 & 441 \\
Ketapang & 449 & 70 & 314 \\
Way Urang & 714 & 90 & 643 \\
Kr. Anyar & 819 & 80 & 655 \\
Jumlah & 3.401 & 73.12 & 2.487 \\
\hline
\end{tabular}

Jumlah ibu hamil saat ini yang tersebar di lima wilayah kerja Puskesmas tercatat sejumlah 3.401, yang ditargetkan ikut KIH 2.487. Masingmasing Puskesmas dalam menetapkan target ibu hamil yang mengikuti kelas ibu hamil tidak sama. Kisaran target yang ditetapkan oleh Puskesmas dalam rentang $50-90 \%$, rata-rata $73,12 \%$.

Pemetaan kelas ibu hamil di tingkat puskesmas sudah melakukan pemetaan daerah secara khusus daerah mana yang akan menjadikan target sasaran pelaksanaan KIH. Seluruh Puskesmas sudah menentukan lokasi desa yang akan membuka KIH, jumlah KIH tiap desa berbeda-beda disesuaikan dengan jumlah kelompok sasaran yaitu jumlah ibu hamil.

\section{Pengalokasian Sumber Daya (Sarana Penunjang dan Pendanaan)}

Paket sarana penunjang KIH (Media Lembar Balik, Buku KIA, panduan senam hamil, matras). Alat bantu edukasi untuk peserta/ibu hamil yaitu buku KIA (pink), hasil pengamatan semua ibu hamil sudah memiliki buku KIA. Alat batu fasilitator dalam pemberian edukasi adalah lembar balik, hasil temuan paket LB belum cukup tersedia, dimana belum semua desa yang melaksanakan kelas ibu hamil tersedia lembar balik. Prasarana lain adalah matras dan tikar, tetapi belum semua KIH prasarana pendukung senam hamil tersedia. Pendanaan program di tingkat kabupaten sudah dipersiapkan dengan rinci kebutuhan dana dalam satu tahun begitu juga perencanaan dana kegiatan program di tingkat puskesmas. Sumber pendanaan pelaksanaan Kelas Ibu Hamil di Tingkat Puskesmas bersumber dari Dana Operasional Puskesmas (DOP) yang diperuntukkan untuk transfortasi petugas dalam pelaksanaan kelas ibu hamil ke tingkat Desa. Sedangkan sumber dana untuk pelaksanaan KIH di tingkat desa dari Puskesmas belum ada dana yang dikhususkan untuk pelaksanaan kegiatan kelas ibu hamil, pembiayaan kelas ibu hamil diperoleh dari dana desa dan swadana masyarakat.

\section{Perencanaan Kelas Ibu Hamil Tingkat Puskesmas dan Desa}

Penanggungjawab program KIH di tingkat Puskesmas adalah koordinator KIH di tingkat Puskesmas, tim pelaksana kelas ibu hamil sudah melibatkan berbagai profesi yang terkait. Penanggung jawab program KIH tingkat Desa adalah bidan Desa, tim pelaksana ada yang melibatkan berbagai profesi yang terkait, dan juga melibatkan kader dan tim PKK. Jumlah bumil yang mengikuti KIH per-angkatan tidak sama, disesuaikan dengan jumlah ibu hamil yang ada 
pada saat itu, rata-rata peserta Kelas Ibu Hamil 10 ibu hamil (kisaran 8-20 ibu hamil) perangkatan.

Jadwal pertemuan pelaksanaan KIH ratarata ditetapkan empat kali pertemuan, dengan waktu pertemuan KIH sebulan sekali, tanggal pelaksanaan ditentukan sesuai dengan kesepakatan dan sudah dibuatkan jadwal setiap bulannya. Materi yang diberikan untuk pertemuan pertama tentang: pemeriksaan kehamilan dan permasalahannya, pertemuan kedua tentang persalinan, pertemuan ketiga bayi baru lahir dan nifas dan pertemuan ke empat yaitu tentang keluarga berencana dan penyakit seksual menular. Pada akhir pertemuan KIH melakukan senam hami bersama selama 15-20 menit.

Fasilitator tetap KIH di tingkat Desa adalah bidan desa. Ada beberapa kelas ibu hamil, fasilitator yang hadir dari Puskesmas tiap tiga bulan dan tiap enam bulan. Sebagian besar bidan desa sebagai fasilitator kelas ibu hamil belum mengikuti pelatihan sebagai fasilitator kelas ibu hamil. Dalam pelaksanaannya KIH dibantu oleh kader kesehatan. Jumlah kader yang ikut berpartisifasi dalam $\mathrm{KIH}$ bervariasi mulai dari satu sampai tiga kader kesehatan.

\section{Komponen Proses}

\section{Sosialisasi}

Sosialisasi Kelas Ibu Hamil di Tingkat Desa, dilakukan oleh bidan desa dan oleh kader kesehatan. Sosialisasi informal ditujukan pada perangkat desa, terutama adalah ibu ketua penggerak PKK ibu lurah, kader posyandu, Lurah dan ibu hamil yang ada di desa. Sosialisasi ini bertujuan memberikan informasi tentang keberadaan $\mathrm{KIH}$ dan memberikan informasi kepada ibu hamil dan keluarganya agar dapat berpartisifasi dalam pelaksanaan kelas ibu hamil.

\section{Pelaksanaan Pertemuan Kelas Ibu Hamil}

Sebelum dimulai edukasi dilakukan pemeriksaan kehamilan (ANC) oleh tim kesehatan. Persepsi di awal pertemuan sebelum pemberian edukasi dilakukan dengan diberikan penjelasan tentang tujuan pertemuan yang akan dicapai. Untuk mengukur capaian edukasi di setiap pertemuan sebelum (Pre-test) dan sesudah (Post-test) tidak dilakukan secara tertulis. Tetapi dilakukan secara lisan dengan cara menanyakan pada ibu hamil yang diketahuinya ataupun pengalamannya tentang materi yang akan disampaikan.

Metode yang digunakan dalam penyampain kelas ibu hamil yaitu: ceramah, diskusi, tanya jawab, dan diselingi dengan curah pendapat. Berbagi pengalaman sesama ibu hamil tentang mengatasi masalah-masalah kehamilan dan persalinan yang pernah dihadapi. Materi yang disampaikan empat kali pertemuan tentang: kehamilan, persalinan, perawatan nifas, dan perawatan bayi baru lahir serta penyakit menular seksual. Alat bantu yang di gunakan untuk menunjang dalam pemberian materi di KIH adalah: lembar balik, buku KIA (buku pink), panduan senam hamil, perlengkapan senam hamil.

Partisipasi suami/pendamping. Saat pelaksanaan $\mathrm{KIH}$ suami/keluarga dianjurkan untuk ikut serta mendampingi ibu minimal satu kali pertemuan. Tetapi dalam pelaksanaannya jarang sekali suami/pendamping untuk aktif mendampingi ibu saat mengikuti kelas ibu hamil, dengan alasan sibuk bekerja dan malu. Setelah selesai pelaksanaan pertemuan edukasi kelas ibu hamil, ibu hamil melakukan senam ibu hamil selama 15-20 menit yang di pandu oleh bidan desa, bertujuan untuk menjaga kebugaran tubuh ibu hamil.

\section{Monitoring dan Evaluasi}

Monitoring pelaksanaan kelas ibu hamil sudah dilakukan di tiap-tiap desa yang melaksanakan KIH. Tim monitoring dari Puskesmas diantaranya: Penanggungjawab program, Kepala Puskesmas, Pokja UKM, Bidan koordinator. Monitoring sudah dijadwalkan secara rutin dan berkala berkisar antara tiga bulan dan enam bulan. Ada Puskesmas yang sudah menyiapkan format monitoring, tapi ada juga yang belum menyiapkan format. Hasil dari monitoring dilakukan feedback untuk masukan pelaksanaan kelas ibu hamil agar lebih baik lagi, tetapi hasil feedback tidak disampaikan secara tertulis hanya lisan saja. Dari hasil wawancara penulis tidak semua Puskesmas melakukan feedback dari kegiatan monitoring. Evaluasi pelaksanaan kelas ibu hamil dilakukan, tetapi tidak secara rutin. Kegiatan-kegiatan yang dievaluasi: evaluasi program mulai dari perencanaan tingkat puskesmas sampai dengan di tingkat desa, pelaksanaan kelas ibu hamil dan hasil kegiatan kelas ibu hamil. Yang melakukan evaluasi program bervariasi antar Puskesmas diantaranya adalah kepala puskesmas, penanggung jawab program kelas ibu hamil, bidan koordinator. Namun tidak semua puskesmas membuat lembar evaluasi. Dokumen pencatatan evaluasi tidak semua puskesmas mendokumentasikannya.

\section{Pencatatan dan Pelaporan}

Pencatatan dan pelaporan pelaksanaan Kelas Ibu Hamil sudah dilakukan di tingkat desa 
pelaksana KIH, dokumen pencatatan dan pelaporan KIH sudh ada di tingkat desa dan dilaporkan ke tingkat Puskesmas. Dokumen yang dicatat dan dilaporkan adalah persentase jumlah ibu hamil yang telah mengikuti kelas ibu hamil, Jumlah kunjungan $\mathrm{K} 1$ dan $\mathrm{K} 4$, persalinan di fasilitas kesehatan dan persalinan di tenaga kesehatan serta perencanaan P4K.

\section{Rencana Tindak Lanjut}

Rencana tindak lanjut setelah empat kali pelaksanaan kelas ibu hamil dilakukan pemantauan ibu hamil yang dilakukan oleh bidan desa. Dilanjutkan dengan Program Perencanaan Persalinan dan Pencegahan Komplikasi (P4k), dengan kegiatan pemasangan stiker yang ditempel di rumah ibu hamil, maka setiap ibu hamil akan tercatat, terdata, dan terpantau secara tepat. Ibu hamil yang tergolong beresiko tinggi dilakukan rujukan ke dokter Puskesmas. Belum ada Puskesmas yang sudah melakukan pengembangan kelas ibu hamil, namun ada beberapa puskesmas yang menginginkan adanya pengembangan kelas ibu hamil yang ditujukan khusus ibu hamil yang tergolong beresiko tinggi.

\section{Komponen Produk}

Jumlah ibu hamil di tahun 2019 tercatat sebanyak 20.467 dan di tahun 2020 menurun menjadi 20.026. Jumlah bayi baru lahir hidup di tahun 2019 sebanyak 18.719 bayi dan tahun 2020 meningkat menjadi 18.403. Persentase angka kematian ibu di tahun 2019 ditemukan sebanyak 8 kasus, dan di tahun 2020 tetap tercatat 8 kasus. Jumlah ibu hamil yang telah mengikuti kelas ibu hamil berkisar antara 40-70\%. Berikut gambaran cakupan pelayanan kesehatan ibu dan anak tahun 2019 dan tahun 2020 di Kabupaten Lampung Selatan.

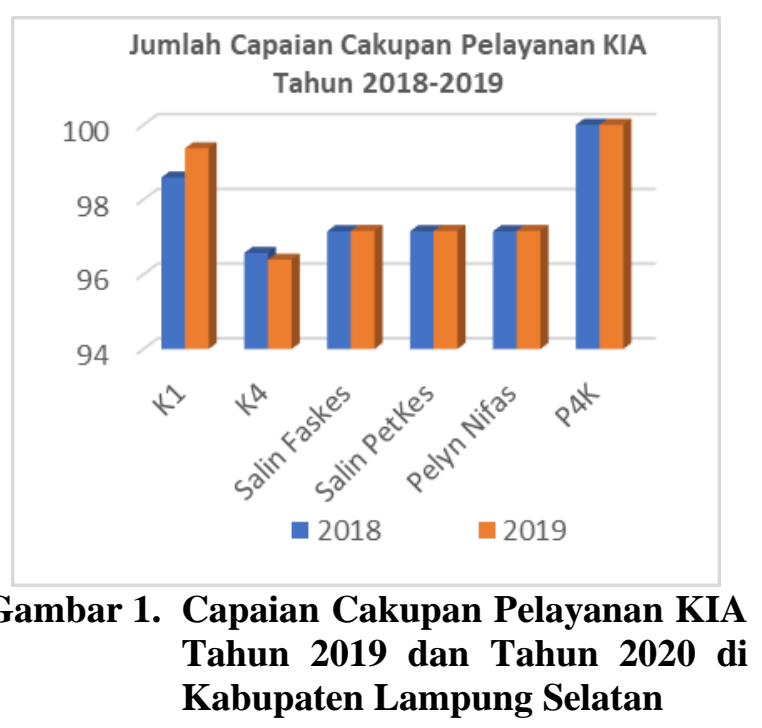

Hasil temuan evaluasi pelaksanaan KIH yang tidak sesuai dengan standar yang memerlukan pengkajian dan pembahasan adalah tentang: 1.Tujuan KIH 2. Penetapan target, 3. Sarana dan prasarana, dan 4. Fasilitator

\section{PEMBAHASAN}

\section{Perencanaan}

Perumusan tujuan program Kelas Ibu Hamil, didasarkan atas empat kriteria evaluasi, didapat tujuan program yang ditetapkan oleh Dinas Kesehatan Lampung Selatan berlandaskan yuridis formal yang jelas, didefinisikan dengan baik, diwujudkan dengan kalimat operasional, dan dikomunikasikan serta dipahami oleh semua. Tetapi dalam rumusannya belum memiliki standar dan batasan waktu yang jelas, sehingga tujuan KIH yang ada belum sesuai dengan kriteria evaluasi yang telah ditetapkan. Perumusan tujuan suatu program berdasarkan pendapat ahli manajemen dan ahli kebijakan publik Colquitt (2014) yaitu:

"Goal defined as the objective or aim of an action and typically refer to attaining a specific standard or proficiency, often within a specified time limit. More specifically, the theory argue that assigning employees specific and difficult goal will result in higher levels of performance than assigning no goals, easy goals, or "do-your-best goals."

Sebagaimana tujuan program KIH yang pertama tertulis "Meningkatkan jumlah ibu hamil yang mengikuti kelas ibu hamil". Seharusnya tujuan tersebut diberi batasan capaian target $50 \%$ di tahun 2020. Sesuai dengan tujuan target program yang telah ditetapkan. Dengan di tuliskan capaian waktu dan target program akan tergolong ke dalam teori motivasi.

\section{Penetapan Target}

Target partisipasi ibu hamil mengikuti KIH untuk di tingkat kecamatan maupun desa, masing-masing menargetkan capaian sesuai dengan kemampuan. Target capaian partisipasi belum ditentukan secara jelas. Menurut Waridah (2017) target adalah "sasaran atau batas ketentuan yang telah ditetapkan untuk dicapai". Target dalam program kesehatan adalah sasaran akhir yang ingin dicapai dari pelaksanaan suatu program. Target biasanya selalu berhubungan dengan tujuan yang ingin dicapai (Sulaiman, 
2019). Penentuan jumlah target sasaran program $\mathrm{KIH}$ yang dibuat oleh Dinas Kesehatan Lampung Selatan sangatlah menentukan akan target capai yang akan dicapai oleh masing-masing Puskesmas sesuai cakupan di wilayah kerjanya. Oleh sebab itu sangatlah diperlukan penentuan target sasaran sesuai dengan pedoman penentuan target sasaran. Dengan dibuatnya jumlah target sasaran secara jelas dan terinci akan menjadikan pedoman bagi petugas dalam memantau sasaran yang belum tercapai.

\section{Sarana Prasarana}

Alat bantu bagi fasilitator dalam penyampaian edukasi di kelas ibu hamil berupa Lembar Balik (LB) dan buku KIA yang di pegang oleh tiap ibu hamil, LB yang tersedia di setiap KIH belum mencukupi dimana belum semua desa yang melaksanakan kelas ibu hamil tersedia lembar balik. Untuk mempercepat penyampaian edukasi pada ibu hamil, sebaiknya menggunakan berbagai macam media edukasi. Penyampaian materi dengan media audio-visual yaitu peberian materi menggunakan kata-kata yang diucapkan dalam bentuk ilustrasi, foto, animasi atau video (Clark \& Mayer, 2016). Dalam menyampaikan materi edukasi dengan media audio-visual lebih disukai karena dilengkapi dengan gambar atau foto yang seolah nyata membuat responden lebih mudah paham (Lenzowski, et al., 2017). Media audio-visual dikatakan baik apabila media tersebut selalu dapat dikembangkan dengan berbagai tahapan sesuai dengan rujukan (Dignan \& Carr, 1992). Penelitian terkait yang mendukung penggunaan audio-visual oleh Sudarmi (2021) yang di dapat penggunaan media audio-visual di kelas ibu hamil lebih efektif dibandingkan dengan penggunaan media lembar balik dalam meningkatkan pengetahuan $(p$-value 0,16$)$ dan merubah sikap $(p$ value 0,000 ) ibu hamil dalam pencegahan komplikasi kehamilan dan persalinan.

\section{Fasilitator}

Fasilitator yang aktif memberikan edukasi pada ibu hamil, mayoritas diberikan oleh profesi bidan. Tim kesehatan lain seperti dokter, penyuluh gizi tidak rutin memberikan edukasi di KIH. Untuk mempercepat peningkatkan pengetahuan dan merubah perilaku ibu hamil kerjasama antar profesi dalam memberikan edukasi sangatlah dibutuhkan. Interprofessional Collaboration (IPC) menurut WHO (2013), ketika banyak petugas kesehatan dari latar belakang profesi yang berbeda, diantaranya dokter, bidan, ahli gizi, ahli sanitasi lingkungan, dan tokoh masyarakat, bekerja sama terhadap pasien, keluarga, dan masyarakat dalam memberikan pelayanan yang berkualitas diharapkan akan mempercepat tujuan dari capaian $\mathrm{KIH}$, yaitu meningkatkan pengetahuan dan merubah perilaku ibu kearah yang lebih positif dalam menjaga kesehatannya.

\section{SIMPULAN}

Secara prosedural pelaksanaan program kelas ibu hamil (KIH) di Kabupaten Lampung Selatan sudah sesuai dengan standar prosedur KIH berdasarkan pedoman kelas ibu hamil oleh Kemenkes RI Tahun 2014. Tetapi secara teknis pelaksanaannya masih ada yang belum sesuai dengan standar diantaranya: 1. Rumusan tujuan belum memiliki standar yang jelas dalam batasan target dan waktu; 2. Penentuan target partisipasi ibu hamil mengikuti KIH belum ada, di setiap Puskesmas menentukan target yang berbedabeda; 3. Alat bantu fasilitator berupa lembar balik dan prasarana penunjang lainnya belum cukup tersedia; 4. Partisipasi peran serta suami/ pendamping $\mathrm{KIH}$ masih kurang; 5. Pelaksanaan monitoring dilakukan, tetapi hasil feedback tidak dilakukan secara tertulis, hanya lisan saja; 6 . Evaluasi pelaksanaan KIH telah dilakukan, tetapi tidak rutin dilaksanakan.

Hendaknya teknis pelaksanaan program $\mathrm{KIH}$ seperti perumusan tujuan program, penentuan target, alat bantu fasilitator, dan pelaksanan monitoring dan evaluasi KIH sesuai dengan standar yang telah ditetapkan. Untuk meningkatkan kualitas fasilitator hendaknya Dinas Kesehatan Lampung Selatan membuat perencanaan pelatihan bagi para fasilitator. Tim pelaksana KIH hendaknya melibatkan profesi kesehatan yang terkait dengan saling berkalaborasi antar profesi (Interprofesional kalaborasi/IPC) dan untuk memantau ibu hamil yang beresiko tinggi hendaknya Dinas Kesehatan Lampung Selatan mengadakan pengembangan model kelas ibu hamil khusus yang beresiko tinggi.

\section{DAFTAR PUSTAKA}

Clark, R.C. \& Mayer, R.E., (2016). E-learning and the science of instruction: proven

guidelines for consumers and designers of multimedia learning (4th Ed.) Canada: 
John Wiley \& Sons Inc.

Colquitt, J., Lepine, J. A., \& Wesson, M. J. (2014). Organizational Behavior: Improving Performance and Commitment in the Workplace (4e). New York, NY, USA: McGraw-Hill.

Dignan, M. B., \& Carr, P. A. (1992). Programme Planning for Health. Malvern, PA: Lee \& Fibiger.

Dinas Kesehatan Lampung Selatan. (2020). Profil dinas kesehatan kabupaten lampung selatan tahun 2019. Lampung Selatan.

Dinas Kesehatan Provinsi Lampung. (2019). Profil Kesehatan Provinsi Lampung Tahun 2018. Bandar Lampung.

Feinstein, L., Sabates, R., Anderson, T.M., Sorhaindo, A., \& Hammond, C. (2006). What are the effects of education on health?. Proceedings of the "Copenhagen Symposium" Measuring the Effects of Education on Health and Civic Engagement.

Fuada, N., \& Setyawati, B. (2015). Pelaksanaan kelas ibu hamil di Indonesia. Indonesian Journal of Reproductive Health, 6(2), 6775

Gueguen, J., Fauvel, G., Luhman, N., \& Bouchon, N. (2010). Health education: A practical guide for health care project

Kementerian Kesehatan RI. (2014). Pedoman, Pelaksanaan Kelas Ibu Hamil. Jakarta: Direktorat Jenderal Bina GIZI dan KIA.

Kementerian Kesehatan RI. (2020). Buku KIA. Kesehatan Ibu dan Anak. Jakarta Kemenkes dan JICA (Japan Internasional Cooperation Agency).

Lenzowski, E., Tung-Hahn, E., Higareda, J., McCormick, C., Markoff, T., Arffa, M., ... Alam, M. (2017). Video education to improve recognition of common benign and malignant cutaneous lesions and skin cancer prevention in the public. International Journal of Women's Dermatology: $\quad 4-6 . \quad \mathrm{http}: / /$ doi.org/10.1016/j.ijwd.2017.10.005

Suarayasa. K. (2020). Strategi menurunkan Angka Kematian Ibu (AKI) di Indonesia, CV. Budi Utama, Yogyakarta.

Sudarmi, S. (2021). Efektifitas Media Audio Visual pada Kelas Ibu Hamil Terhadap Pengetahuan dan Sikap Ibu dalam Pencegahan Komplikasi Kehamilan dan Persalinan. Jurnal Kesehatan Metro Sai Wawai, 14(1), 19-29.

Sulaiman, E. S. (2019). Manajemen Kesehatan. Edisi kedua. Yogyakarta: Universitas Gajah Mada Press.

Waridah, Ernawati, S. S. (2017). Kamus Bahasa Indonesia. Bmedia.

WHO, UNICEF, UNFPA, World Bank Group and the United Nations Population Division. (2019). Maternal mortality: Levels and trends 2000 to 2017. Geneva. https://www.who.int/reproductivehealth/pu blications/maternal-mortality-20002017/en/

WHO. (2015). Global Health Observatory (GHO) data: Under-five mortality. http://www.who.int/gho/child_health/morta li ty/mortality_under_five/en/

WHO. (2013). Interprofessional Collabotative Practice in Primary Health Care. Six Case Studies. Human Resouurces for Health, Issue No.13. Geneva, Switzerland.

Yin, R.K. (2012). Case Study Research Design and Methods Fourth Edition. USA: SAGE Publication. 